\title{
AÇÕES DE EDUCAÇÃO AMBIENTAL REALIZADAS NO ÂMBITO DE TRÊS UNIDADES DE CONSERVAÇÃO DO RIO GRANDE DO SUL
}

\author{
Mônica Pissatto ${ }^{1}$, Ana Maria Thielen Merck ${ }^{2}$, Cibele Rosa Gracioli ${ }^{3}$ \\ ${ }^{1}$ Engenheira florestal \\ ${ }^{2}$ Profa Dra Adjunta do Depto de Biologia UFSM \\ ${ }^{3}$ Profa Dra Adjunta, Campus de São Grabiel, UNIPAMPA \\ 1monicapissatto@yahoo.com.br
}

Palavras-chave: Unidades de Conservação; Educação ambiental; legislação ambiental; gestão ambiental.

As Unidades de Conservação (UCs) são reservas criadas pelo Estado com os objetivos principais de proteção e uso sustentável dos recursos naturais e manutenção da biodiversidade, dentre outros também tem o objetivo de favorecer condições e promover a educação ambiental e a interpretação ambiental (BRASIL, 2000). O objetivo desta pesquisa foi obter dados sobre a efetividade de ações de educação ambiental (EA) dos programas de gestão das Florestas Nacionais (FLONAS) de Passo Fundo e de São Francisco de Paula e da Área de Proteção Ambiental (APA) de Ibirapuitã no RS. Foi realizada uma análise do conteúdo de questionários, com questões abertas, realizado pelo Instituto Chico Mendes de Conservação da Biodiversidade no ano de 2008, visando obter informações sobre os processos educativos em curso no Instituto. A pesquisa demonstrou que o desenvolvimento de ações de EA iniciou recentemente nas UCs de Passo Fundo e de Ibirapuitã (2003 e 2004) e estas foram realizadas pelos respectivos gestores. Estes gestores possuem formação relacionada à EA no processo de gestão ambiental, o que contribuiu para o enfoque atual de suas ações, direcionadas principalmente para a comunidade local visando a sua participação no processo de gestão das UCs. Nestas UCs foram formadas parcerias para o desenvolvimento das ações. Na UC de Ibirapuitã as principais atividades de EA realizadas foram palestras e oficinas em eventos relacionados ao Meio Ambiente e a elaboração de projeto visando formar multiplicadores ambientais nas comunidades escolares da região. $\mathrm{Na}$ UC de Passo Fundo as principais atividades realizadas foram distribuição de mudas junto à comunidade escolar, implantação de horto de plantas bio-ativas, desenvolvimento de dois projetos, um com objetivo de promover a conservação da biodiversidade da UC e outro visando a formação dos membros do conselho gestor para a sua participação no processo de gestão ambiental da reserva. Na UC de São Francisco de Paula são realizadas ações de EA desde a década de 60, atualmente estas ações são desenvolvidas pelo respectivo gestor, que não possui formação na área de EA. $O$ enfoque dado foi o atendimento a demanda de visitantes, através de sua condução pelas trilhas da reserva e a realização de palestras. Conforme os gestores a realização de ações de EA promoveu a mudança da perspectiva do público em relação as UCs e ao órgão ambiental, contribuindo no sentido de preservação destes ambientes. Porém, foi evidenciada a dificuldade para a realização das ações voltadas a esta temática, atribuída a falta de recursos humanos e financeiros específicos. Portanto, apesar de estar entre os objetivos das UCs, observa-se que a promoção de ações de EA foi secundarizada. A valorização das ações voltadas a esta temática é essencial para que as reservas cumpram as funções pelas quais foram criadas. Uma das formas de promover esta valorização é trabalhar para que estas ações tenham um melhor acompanhamento e avaliação de sua 
efetividade. A disponibilização das informações geradas pelos projetos realizados para a consulta ao público e a atuação na formação das parcerias contribuiria para a continuidade e efetividade destes trabalhos.

\section{INTRODUÇÃO}

As Unidades de Conservação (UCs) podem ser definidas como porções do território de uso restrito pelo Estado, onde a possibilidade de utilização dos recursos naturais é dependente da categoria na qual a área está inserida. As UCs podem ser de proteção integral ou de uso sustentável, existindo ainda várias categorias dentro destes dois grandes grupos, cada uma com suas especificidades.

De acordo com o Sistema Nacional de Unidades de Conservação da Natureza, instituído pela Lei Federal 9.985/2000, os principais objetivos das UCs de proteção integral são a proteção total dos recursos naturais e do ecossistema e o incentivo ao seu uso indireto, que compreende a realização de pesquisas científicas, atividades de educação ambiental, interpretação ambiental, turismo ecológico e recreação. Enquanto as UCs de uso sustentável têm o objetivo básico de manutenção dos ecossistemas compatibilizando com a exploração sustentável de seus recursos naturais, o que deve ser realizado através do cumprimento das orientações constantes nos Planos de Manejo destas reservas.

Desta forma, presume-se que o incentivo e a promoção da educação ambiental e de estratégias de integração com a população local e visitante no âmbito das UCs são ações fundamentais para que estas áreas exerçam as suas funções, pois o reconhecimento das funções exercidas pela reserva pela população e o incentivo ao seu envolvimento com atividades desenvolvidas no âmbito da UC pode contribuir para a preservação e manutenção destas áreas.

A educação ambiental é um processo que consiste em propiciar às pessoas uma compreensão crítica e global do meio ambiente, para elucidar valores e desenvolver atitudes que Ihes permitam adotar uma posição crítica e participativa a respeito das questões relacionadas com a conservação e adequada utilização dos recursos naturais, para melhoria da qualidade de vida e a eliminação da pobreza extrema e do consumismo desenfreado (MEDINA, 1997).

A educação ambiental direcionada à comunidade tem como objetivo o desenvolvimento de atividades e práticas educativas ao longo de toda a vida do indivíduo, que o sensibilize sobre as questões ambientais e as consequências destas sobre a qualidade de vida da comunidade, constituindo um processo permanente de formação, para que os indivíduos atuem como formadores de opinião em suas comunidades (MERCK, 2009).

O desenvolvimento de práticas de interpretação ambiental e programas de educação ambiental em UCs podem favorecer os processos indutores de maior nível de conscientização ambiental, e o nível de conscientização ambiental pode ser considerado como pré-requisito para uma efetiva conservação da natureza (MACEDO et al, 2005).

As ações educativas em unidades de conservação têm o papel de promover o entendimento da comunidade em geral, acerca da importância ecológica, econômica e social destas reservas e assim contribuir para a valorização destes ambientes pela população. A conservação da reserva é bastante influenciada pela percepção e identificação da população em relação a esta área. Sendo assim, as ações educativas podem ser uma ferramenta eficaz para que as UCs tornem-se realmente efetivas e cumpram os objetivos pelos quais foram criadas.

Algumas Políticas Públicas relacionadas com a questão socioambiental, como a Política 
Nacional do Meio Ambiente (Lei 6.938/81), a Política Nacional da Educação Ambiental (Lei 9.795/99), o Sistema Nacional de Unidades Conservação da Natureza (Lei 9.985/2000), o Sistema Estadual de Unidades de Conservação do Rio Grande do Sul (Decreto 34.256/1992) salientam em seus princípios, objetivos ou em outros artigos a importância da promoção da educação ambiental no âmbito das UCs.

Desta forma, o objetivo desta pesquisa foi obter dados sobre a efetividade das ações de educação ambiental no âmbito dos programas de gestão de três UCs do Rio Grande do Sul: Área de Proteção Ambiental (APA) de Ibirapuitã, Floresta Nacional (FLONA) de São Francisco de Paula e Floresta Nacional (FLONA) de Passo Fundo.

\section{METODOLOGIA}

Na primeira etapa, foi realizada uma revisão bibliográfica sobre aspectos gerais das UCs no Brasil e no Rio Grande do Sul através de pesquisa nas páginas virtuais do Ministério do Meio Ambiente (MMA), Instituto Chico Mendes de Conservação da Biodiversidade (ICMbio) e Secretaria Estadual do Meio Ambiente do Rio Grande do Sul (SEMA), e em artigos e trabalhos científicos. Após, foi realizada uma pesquisa bibliográfica referente a importância da educação ambiental para a consolidação das UCs, as políticas públicas institucionalizadas que relacionam as reservas com a educação ambiental (EA) e os programas de educação ambiental constantes nos planos de manejo das UCs disponibilizados pela Secretaria Estadual do Meio Ambiente do Rio Grande do Sul (SEMA).

Em seguida, foi realizada uma análise do conteúdo de questionários, composto de questões abertas, realizado pelo Instituto Chico Mendes de Conservação da Biodiversidade (ICMbio) em 2008, com o objetivo de obter dados sobre os processos educativos em curso no âmbito deste instituto. Este questionário é relativo aos aspectos estruturais das ações, seus focos e sujeitos prioritários e as mudanças e limitações associadas ao desenvolvimento das atividades de educação ambiental.

As UCs contempladas por esta pesquisa, realizada pelo Instituto Chico Mendes de Conservação da Biodiversidade (ICMbio), no Rio Grande do Sul foram as FLONAS de São Francisco de Paula e de Passo Fundo e a APA de Ibirapuitã. Os questionários foram respondidos pelos gestores das reservas. 


\section{RESULTADOS E DISCUSSÃO}

\subsection{Características das ações de educação ambiental realizadas nas UCs}

A tabela 1 demonstra as características principais das ações de educação ambiental realizadas nas três reservas, Área de Proteção Ambiental (APA) de Ibirapuitã e as Florestas Nacionais (FLONAS) de São Francisco de Paula e de Passo Fundo, enfocando os aspectos estruturais das ações, seu foco e sujeitos prioritários e as mudanças e limitações associadas ao desenvolvimento das atividades de educação ambiental.

Tabela 1 - Características das ações de educação ambiental realizadas na Floresta Nacional de São Francisco de Paula (FLONA de São Francisco), na Área de Proteção Ambiental de Ibirapuitã (APA de Ibirapuitã) e na Floresta Nacional de Passo Fundo (FLONA Passo Fundo).

\begin{tabular}{|c|c|c|c|}
\hline & $\begin{array}{c}\text { FLONA } \\
\text { São Francisco }\end{array}$ & $\begin{array}{c}\text { APA } \\
\text { Ibirapuitã }\end{array}$ & $\begin{array}{c}\text { FLONA } \\
\text { Passo Fundo }\end{array}$ \\
\hline Época de início das ações & Anos 60 & 2004 & 2003 \\
\hline Agentes das ações & Servidores & Servidor e Parceria & Servidor e Parceria \\
\hline $\begin{array}{c}\text { Formação em educação } \\
\text { ambiental }\end{array}$ & Não & Sim & Sim \\
\hline Características da parceria & Sem parceria & $\begin{array}{l}\text { Parceria não formal } \\
\text { com sindicato de } \\
\text { professores }\end{array}$ & $\begin{array}{l}\text { Parceria com } \\
\text { integrantes do } \\
\text { conselho gestor }\end{array}$ \\
\hline Fontes de Recursos & Sem recursos específicos & Parceria e ICMBio & $\begin{array}{c}\text { Sem recursos } \\
\text { específicos }\end{array}$ \\
\hline Focos das ações & Demanda de grupos visitantes & $\begin{array}{l}\text { Formação de } \\
\text { multiplicadores } \\
\text { ambientais para } \\
\text { trabalhar gestão } \\
\text { ambiental pública }\end{array}$ & $\begin{array}{l}\text { Formação do conselho } \\
\text { gestor e projetos } \\
\text { educativos voltados a } \\
\text { comunidade }\end{array}$ \\
\hline Principais sujeitos das ações & Estudantes visitantes & $\begin{array}{c}\text { Comunidade escolar e } \\
\text { comunidade local }\end{array}$ & $\begin{array}{c}\text { Membros do conselho } \\
\text { gestor e comunidade } \\
\text { local e escolar }\end{array}$ \\
\hline $\begin{array}{l}\text { Principais atividades } \\
\text { realizadas }\end{array}$ & Palestras e condução por trilhas & $\begin{array}{l}\text { Palestras e oficinas em } \\
\text { eventos relacionados } \\
\text { ao meio ambiente, } \\
\text { elaboração de projeto } \\
\text { educativo }\end{array}$ & $\begin{array}{l}\text { Projeto de formação } \\
\text { do conselho } \\
\text { consultivo, distribuição } \\
\text { de mudas, implantação } \\
\text { de horto de plantas } \\
\text { bio-ativas, projeto } \\
\text { voltado a conservação } \\
\text { da biodiversidade }\end{array}$ \\
\hline $\begin{array}{c}\text { Mudanças observadas após } \\
\text { realização das ações } \\
\text { educativas }\end{array}$ & Percepção da função da UC & $\begin{array}{l}\text { A APA e o IBAMA } \\
\text { passam a ser vistos } \\
\text { como parceiros }\end{array}$ & $\begin{array}{c}\text { Percepção da função } \\
\text { da UC, maior interesse } \\
\text { em participar }\end{array}$ \\
\hline Limitações encontradas & Falta de pessoal & $\begin{array}{l}\text { Impossibilidade de } \\
\text { dedicar mais tempo }\end{array}$ & $\begin{array}{l}\text { Falta de pessoal e } \\
\text { recursos financeiros }\end{array}$ \\
\hline
\end{tabular}

Fonte: Questionário cedido pelo ICMbio, 2008.

Como pode ser observado na tabela 1 a realização de ações de educação ambiental é recente nas UCs de Passo Fundo e Ibirapuitã, com início em 2003 e 2004 respectivamente. Na UC de São Francisco de Paula são realizadas ações de educação ambiental desde a década de 60. 


\section{Revista Eletrônica em Gestão, Educação e Tecnologia Ambiental} REGET/UFSM (e-ISSN: 2236-1170).

Na FLONA de São Francisco as atividades educativas foram realizadas pelo gestor da reserva. Nesta UC não foi estabelecida parceria para a realização das ações de educação ambiental. A formação de parcerias foi observada nas outras duas reservas, o que pode estar relacionado ao curso de formação em educação ambiental realizado pelos gestores destas UCs.

Nas UCs de Passo Fundo e de Ibirapuitã as ações educativas foram realizadas pelos gestores, ambos com curso de formação em educação ambiental no processo de gestão ambiental. Pode-se observar que este curso de formação influenciou no enfoque das ações de educação ambiental priorizado pelos gestores destas UCs, que as direcionaram para a comunidade, visando sua participação no processo de gestão ambiental. Isto pode ser observado pelas parcerias formadas para o desenvolvimento das ações de educação ambiental e pelos projetos em andamento e em elaboração no âmbito das gestões.

A gestão da FLONA de Passo Fundo estabeleceu parceria através de acordo com os integrantes do conselho gestor, formado por universidades da região, EMATER, prefeitura e outros grupos locais e a APA formou parceria informal com o sindicato de professores. Nestas reservas há a perspectiva de busca por mais parceiros. Com relação ao monitoramento do trabalho desenvolvido pelos agentes parceiros, na APA de Ibirapuitã não é realizado o monitoramento e na FLONA de Passo Fundo as ações desenvolvidas são monitoradas pelo administrador da reserva e pelos membros do conselho consultivo.

A formação de parcerias para o desenvolvimento de ações de educação ambiental é um fator positivo, pois permite que entidades e grupos da comunidade local se aproximem e tenham um maior vínculo com a reserva. Esta ação possibilita que a comunidade identifique-se com estes ambientes e seja esclarecida quanto as sua função de existência, além disto, pode estimular a participação da comunidade na manutenção da qualidade ambiental das UCs.

A participação ativa da comunidade é fundamental, porém, é necessária a criação de mecanismos educacionais eficientes que realmente incentivem o exercício de cidadania da comunidade para a manutenção dos ambientes (SATO, 2001 apud SATO e PASSOS, 2001).

A democratização do processo de gestão das UCs é garantida através da existência dos conselhos que possibilitam a participação igualitária dos diferentes agentes sociais envolvidos no processo decisório. Porém para que isto seja possível é necessário o desenvolvimento de ações de mobilização, envolvimento e formação que propiciem a todos os membros do conselho uma intervenção qualificada (LOUREIO et al, 2007).

O processo de formação, capacitação e renovação dos membros dos conselhos das reservas é uma perspectiva futura das gestões das três UCs.

Os gestores das três UCs contempladas com a pesquisa observaram que a realização das ações de educação ambiental promoveu mudanças na relação do público com as UCs. Ocasionando a alteração de percepção destes sujeitos em relação as áreas protegidas. Foram observadas mudanças positivas na percepção da função das UCs e do órgão ambiental.

Neste sentido, Rylands e Brandon (2005) observam que a efetividade de cada reserva depende da visão da comunidade local sobre estes ambientes, se vistos como um benefício ou como um empecilho.

Queiroz (2005) observa que os níveis de proteção e conservação atuais da UC Mamiraúa, na Amazônia, jamais seriam possíveis sem que a população local fosse adequadamente envolvida e esclarecida transformando-se em parceira efetiva das ações desenvolvidas pelo projeto na reserva.

Em relação às limitações encontradas para a realização das ações educativas evidenciou-se a falta de pessoal e a carência de recursos financeiros específicos para o seu desenvolvimento, 
citado nas UCs de Passo Fundo e de São Francisco de Paula. Na APA de Ibirapuitã a limitação salientada foi a indisponibilidade de tempo para o desenvolvimento das ações voltadas a temática da educação ambiental, o que também pode ser interpretado como falta de recursos humanos.

A secundarização atribuída à temática educação ambiental no âmbito da gestão das UCs reflete as dificuldades evidenciadas para a realização das ações de educação ambiental. Contudo, a valorização desta temática é essencial para que estas áreas cumpram os objetivos básicos de sua criação, que correspondem a proteção dos recursos naturais e do ecossistema e o incentivo ao seu uso indireto, no caso das UCs de proteção integral, e manutenção dos ecossistemas compatibilizando com a exploração sustentável de seus recursos naturais, no caso das UCs de uso sustentável.

A priorização da motivação e formação dos gestores para que estes atuem como multiplicadores ambientais junto a população, promovendo a sua sensibilização e informação para que esta reconheça e compreenda a importância destas áreas protegidas, pode contribuir para que a comunidade atue como aliada das UCs, se sentindo também responsável pela manutenção da qualidade ambiental das reservas e participando no processo de gestão ambiental.

Com o esclarecimento e sensibilização da população local a cerca das funções ecológicas, ambientais, sociais e econômicas exercidas pelas UCs é possibilitado que representantes da própria comunidade atuem como multiplicadores ambientais e formadores de opinião e também como parceiros no desenvolvimento de projetos de educação ambiental, através de instituições locais, como ONGs e universidades.

\subsubsection{Focos e sujeitos das ações}

Floresta Nacional de Passo Fundo

Na FLONA de Passo Fundo o foco dos trabalhos no contexto da gestão foi a formação do conselho consultivo e a realização de projetos educativos voltados a comunidade local. Estes focos e sujeitos foram eleitos pelo fato de serem considerados os sujeitos prioritários para a ação no momento atual da unidade.

As atividades realizadas pela gestão envolveram um encontro para formação do conselho gestor da UC, projeto que estava sendo iniciado no período da realização do questionário e tem como objetivo principal promover a capacitação dos integrantes do conselho para gestão participativa da UC. Também foram realizadas a distribuição de mudas junto a comunidade escolar, atividade anual, a implantação de horto de plantas bio-ativas, realizada em parceria com grupos locais, e o desenvolvimento de projeto voltado a conservação da biodiversidade na UC, também em parceria com vários grupos da região. 


\section{Revista Eletrônica em Gestão, Educação e Tecnologia Ambiental}

REGET/UFSM (e-ISSN: 2236-1170).

\section{Floresta Nacional de São Francisco de Paula}

Nesta UC o foco das ações educativas no contexto da gestão foi o atendimento a demanda de visitantes, formados principalmente por grupos de estudantes provenientes de escolas e universidades de todo o Rio Grande do Sul. Foi realizada a condução de estudantes pelas trilhas da reserva e também foram desenvolvidas palestras durante todo o ano. O motivo para a escolha deste foco foi a demanda obtida e a absoluta falta de recursos humanos para a realização de projetos adicionais.

Área de Proteção Ambiental Ibirapuitã

O foco principal das ações educativas no contexto da gestão direcionou-se para a capacitação da comunidade local visando a sua participação na gestão ambiental da APA.

Para isto, estava em elaboração pela gestão em parceria com os professores da região, um projeto que tem como objetivo capacitar multiplicadores ambientais, ligados a comunidade escolar. O objetivo deste projeto é envolver e sensibilizar a comunidade escolar para que esta atue como multiplicadora ambiental junto aos moradores da região da bacia hidrográfica contemplada.

Anteriormente foram realizadas palestras e oficinas de educação ambiental em seminário sobre educação, atividade anual, e em conferência sobre meio ambiente, atividade que ocorre a cada dois anos. Estas ações foram realizadas junto a comunidade escolar municipal. Nestes espaços educativos a própria comunidade escolar refletiu e discutiu os problemas socioambientais relacionados a sua bacia hidrográfica. Desta forma, o gestor da UC atribuiu a escolha do foco e sujeitos para as ações de educação ambiental atuais como forma de dar continuidade aos trabalhos realizados pelas escolas nos espaços educativos.

\section{CONCLUSÃO}

Foram desenvolvidas ações de educação ambiental no âmbito das UCs analisadas, visto que a promoção da educação ambiental é um de seus principais objetivos. Entretanto, pode-se observar através desta pesquisa que a realização de atividades de EA foi secundarizada dentro dos programas de gestão, isso foi evidenciado devido as limitações salientadas para a realização das ações voltadas a esta temática.

A secundarização atribuída à temática educação ambiental é um reflexo das limitações encontradas para a realização destas ações. Mesmo assim, a valorização desta temática é essencial para que as UCs sejam efetivas. A priorização da motivação e formação dos gestores para que estes atuem como multiplicadores ambientais junto a população, promovendo o seu esclarecimento e sensibilização para que esta compreenda a importância destas áreas protegidas, torna possível que a própria comunidade atue como multiplicadora ambiental e formadora de opinião e se torne parceira no desenvolvimento de projetos de educação ambiental no âmbito da reserva.

A promoção da atuação de ONGs, universidades, e outros grupos da região, é uma alternativa para que a população se torne ativa na elaboração e desenvolvimento de projetos de educação ambiental, possibilitando o seu envolvimento com atividades possíveis de serem desenvolvidas nas UCs.

O estabelecimento de parcerias para a realização destas ações mostrou-se a estratégia 
utilizada em duas UCs. A atuação na formação destas parcerias pode contribuir para a efetividade e continuidade do desenvolvimento das ações de educação ambiental.

As ações de educação ambiental devem ter um sentido de continuidade e para isto é necessário um constante acompanhamento e avaliação de sua efetividade. Além disto, a disponibilização das informações geradas por estes trabalhos para a consulta ao público também pode contribuir para que os projetos tenham continuidade.

A realização de trilhas é desenvolvida em uma UC, esta atividade pode despertar o público visitante para que compreendam a função da reserva e busquem realizar atividades em contato com a natureza no ambiente das UCs, aproximando a comunidade das áreas protegidas e possibilitando estimular a população para que participe das atividades realizadas na reserva, como no desenvolvimento de trilhas e no processo de gestão.

\section{REFERÊNCIAS BIBLIOGRÁFICAS}

BRASIL. Lei n. 9.985, de 18 de julho de 2000. Institui o Sistema Nacional de Unidades de Conservação da Natureza. Brasília, DF, 18 de julho, 2000. Disponível em:

http://www.planalto.gov.br/ccivil 03/Leis/L9985.htm. Acesso em: 15 de maio de 2010.

. Lei n. 9.795, de 27 de abril de 1999. Institui a Política Nacional de Educação Ambiental. Brasília, DF, 27 de abril, 1999. Disponível em: http://www.planalto.gov.br/ccivil/Leis/L9795.htm . Acesso em: 01 de junho de 2010.

. Lei n. 6.938, de 31 de agosto de 1981. Dispõem sobre a Política Nacional do Meio Ambiente. Brasília, DF, 31 de ago. 1999. Disponível em: http://www.planalto.gov.br/ccivil 03/Leis/L6938.htm. Acesso em: 01 de junho de 2010.

LOUREIO, C.F. AZAZIEL,M.; FRANCA,N. Educação ambiental e conselho em unidades de conservação: aspectos teóricos e metodológicos. Rio de Janeiro: IBASE, 2007.

MACEDO, R.L.G; MACEDO, S.B; VENTURIN, N; ANDRETTA, V; AZEVEDO, F.C.S. Pesquisa de percepção ambiental para o entendimento e direcionamento da conduta ecoturística em unidades de conservação. Congresso interdisciplinar de ecoturismo em unidades de conservação, 2.; Congresso nacional de ecoturismo, 6. 2005, Itatiaia. Disponível em: <www.physis.org.br/ecouc/isncricoes.html>. Acesso em 09 de setembro de 2011.

MEDINA, N.M. Educação ambiental para o século XXI e a construção do conhecimento: suas implicações na educação ambiental. n.12. Brasília: IBAMA, 1997. 38 p. (Série Meio Ambiente em Debate). Disponível em: <http://www.ibama.gov.br/edicoes/site/pubLivros/serie_12.pdf>. Acesso em: maio de 2010.

MERCK, A.M. Metodologias Interdisciplinares em Educação ambiental. Cadernos didáticos UFSM- ETIC. Santa Maria, 2009.

QUEIROZ, H.L. A Reserva de desenvolvimento sustentável Mamirauá. Estudos avançados. v. 19, n. 54, maioago, 2005. Disponível: <http://www.scielo.br/scielo.php?pid=S0103-

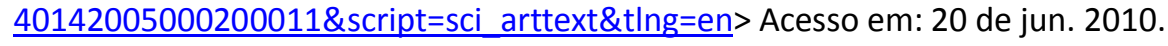

RIO GRANDE DO SUL. Decreto n. 34.256 de 02 de abril de 1992. Cria o Sistema Estadual de Unidades de 
PISSATTO et al., v(5), n5, p. 804 - 812, 2012.

Revista Eletrônica em Gestão, Educação e Tecnologia Ambiental

REGET/UFSM (e-ISSN: 2236-1170).

Conservação e dá outras providências. Disponível em:

http://www.sema.rs.gov.br/sema/html/dec 34256.htm. Acesso em: 15 de maio de 2010

RYLANDS, A.B.; BRANDON, K. Unidades de Conservação brasileiras. Megadiversidade, v.1, n.1, julho, 2005. Disponível em: < http://www.conservacao.org/publicacoes/files/06_rylands_brandon.pdf> Acesso em: 21 de junho de 2010

SATO, M. Apaixonadamente pesquisadora em Educação Ambiental. Educação: Teoria e Prática, v. 9, n. 16, jan - jun 2001 e n. 17, jul - dez, 2001. 